\title{
Bilateral and multifocal phyllodes tumours of the breast: A case report
}

\author{
Shane KF Seal MD FRCSC, Urve Kuusk MD FRCSC, Peter A Lennox MD FRCSC
}

\begin{abstract}
SKF Seal, U Kuusk, PA Lennox. Bilateral and multifocal phyllodes tumours of the breast: A case report. Can J Plast Surg 2010;18(4):145146.

Phyllodes tumours are rare breast neoplasms that present as painless breast masses. They are classified as benign, malignant and borderline. More rare presentations of these tumours include bilateral asynchronous disease and unilateral multifocal disease. Surgical excision with clear margins remains the treatment of choice for these tumours. The present case report is the first to be discussed in the literature. It describes a patient presenting with synchronous bilateral, multifocal breast phyllodes tumours who underwent immediate reconstruction with tissue expanders at the time of her mastectomies.
\end{abstract}

\section{Tumeurs phyllodes bilatérales et multifocales du sein : Rapport de cas}

Les tumeurs phyllodes sont de rares néoplasies mammaires qui prennent la forme de masses indolores aux seins. On les classe parmi les catégories bénigne, maligne et limite. Parmi les tableaux plus rares de ces tumeurs, mentionnons la maladie bilatérale asynchrone et l'atteinte unilatérale multifocale. L'exérèse chirurgicale avec marges claires reste le traitement de choix de ces tumeurs. Le présent rapport de cas est le premier à être abordé dans la littérature. Il décrit une patiente présentant des tumeurs phyllodes synchrones bilatérales multifocales qui a subi une reconstruction immédiate avec expanseurs tissulaires au moment de ses mastectomies.

Key Words: Breast neoplasm; Phyllodes tumour

Phyllodes tumours (PTs) are rare breast neoplasms, comprising an estimated $0.5 \%$ of all primary breast tumours (1). These neoplasms generally present as unilateral painless, well-circumscribed, mobile breast masses in women 35 to 55 years of age (2). Bilateral tumours are rare and tend to be asynchronous in nature (3). PTs are classified according to their biological behaviour: benign, malignant and borderline (4). These are locally aggressive tumours with a high recurrence rate. Surgery is the main treatment modality (2). The presence of clear margins is the most reliable predictor for local control; mastectomy has more success than breast-conserving surgery in borderline and malignant cases (5). A small percentage of these tumours are malignant. The role of chemotherapy and radiotherapy is controversial (4). Distant metastases are uncommon, occurring in 3\% to $13 \%$ of cases; the most common site is the lung (1).

We present a case of bilateral, synchronous, multifocal disease in a healthy 42-year-old woman. We believe the present case is the first to be reported in the literature.

\section{CASE PRESENTATION}

The patient was a 42-year-old woman who presented with multiple bilateral breast masses that she had noted over the previous 12 months; she was referred to a community general surgeon. Her routine annual mammogram confirmed new bilateral, noncalcified masses when compared with the previous investigation. In 1991, the patient was previously seen by one of the authors (UK); she presented with multiple masses in both breasts that were clinically diagnosed as fibroadenomas. At that time, she refused biopsy or removal of these masses. There was no family history of breast cancer. Clinical examination featured a large mass in the right upper breast with two additional smaller palpable masses in proximity to the areola. The left breast had two mobile masses in the lower outer quadrant and thickening in the superior region. The large mass on the right breast had a core biopsy performed that showed benign PTs. A subsequent ultrasound demonstrated multifocal bilateral masses.

The patient underwent surgery by her primary general surgeon for local excision of these masses. This was achieved via circumareolar incisions. Three palpable masses on the right and four palpable masses on the left were removed and sent for pathological assessment. The largest mass was from the right breast and measured $5 \mathrm{~cm} \times 4 \mathrm{~cm} \times 3 \mathrm{~cm}$. The other masses were $2.5 \mathrm{~cm}$ in diameter. All masses were benign PTs. The lesions extended to the edge of the tissue specimens in all submitted specimens. Following this surgery, there were fewer palpable masses. However, ultrasound demonstrated multiple residual lesions, and one mass in the peripheral left breast showed rapid growth.

The patient was referred to the BC Cancer Agency and to a surgical oncologist (UK). It was believed that local control could not be achieved without bilateral mastectomies due to the multifocal nature of the disease. The patient was also referred to a reconstructive plastic surgeon (PAL), and elected to proceed with a two-stage nonautologous reconstruction with tissue expander insertion at the time of the mastectomies after discussing her reconstructive options. Pathological examination

Department of Surgery, Division of Plastic Surgery, University of British Columbia, Vancouver, British Columbia

Correspondence: Dr Shane KF Seal, Department of Surgery, Memorial University, PO Box 23104, Churchill Square, St John's,

Newfoundland and Labrador A1B 4J9. Telephone 709-754-6165, fax 709-754-8262, e-mail shanekfseal@yahoo.com 


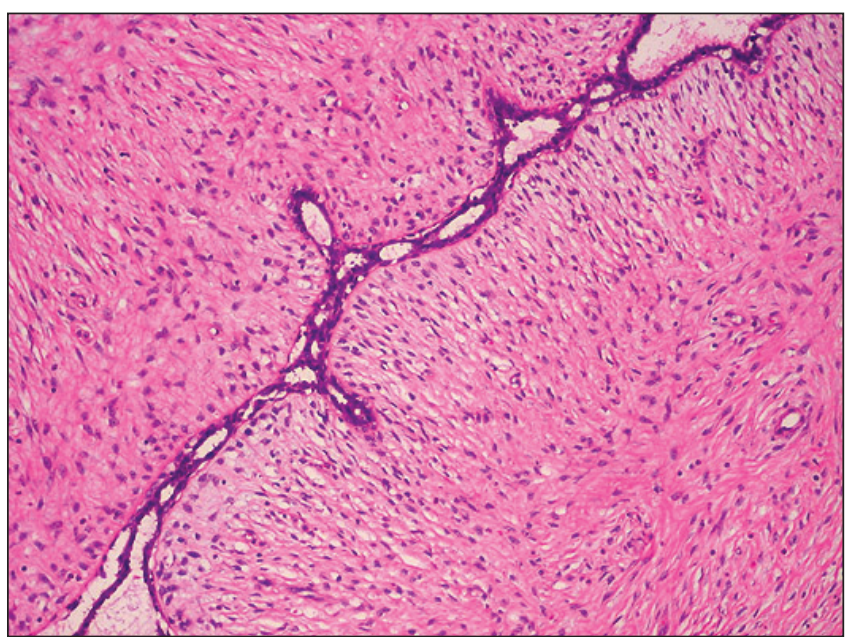

Figure 1) Left breast phyllodes tumour showing 'leaf-like' appearance on microscopy

confirmed all masses in both breasts as benign PTs with clear margins (Figures 1 and 2).

\section{CONCLUSION}

The current report presents an interesting and previously unpublished case of synchronous benign, bilateral, multifocal PTs requiring bilateral mastectomies for successful management. The patient underwent immediate nonautologous reconstruction.

ACKNOWLEDGEMENTS: The authors thank Dr Malcolm Hayes at the BC Cancer Agency for his assistance with pathology specimen handling and analysis.

FUNDING: The authors have no financial support to declare.

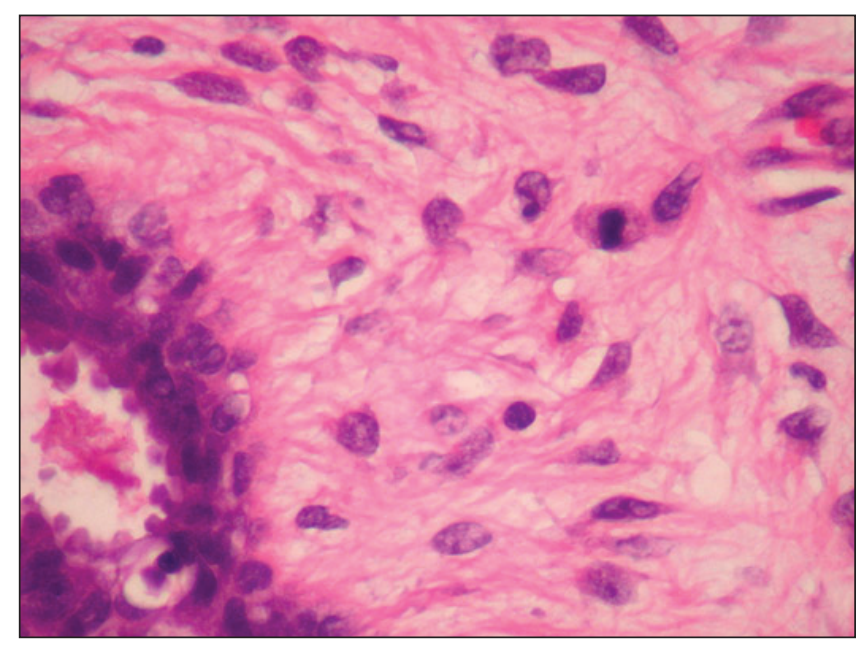

Figure 2) Right breast phyllodes tumour showing mitoses

\section{REFERENCES}

1. Keelan PA, Myers JL, Wold LE, et al. Phyllodes tumor: Clinicopathologic review of 60 patients and flow cytometric analysis in 30 patients. Hum Pathol 1992;23:1048-54.

2. Ben Hassouna J, Damak T, Gamoudi A, et al. Phyllodes tumors of the breast: A case series of 106 patients. Am J Surg 2006;192:141-7.

3. Mrad K, Driss M, Maalej, et al. Bilateral cystosarcoma phyllodes of the breast: A case report of malignant form with contralateral benign form. Ann Diagn Pathol 2000;4:370-2.

4. Chen WH, Cheng SP, Tzen CY, et al. Surgical treatment of phyllodes tumors of the breast: Retrospective review of 172 cases. J Surg Oncol 2005;91:185-94.

5. Belkacemi Y, Bousquet G, Marsiglia H, et al. Phyllodes tumor of the breast. Int J Radiation Oncology Biol Phys 2008;70:492-500. 